Research Article

\title{
Experimental Study on FRP-to-Concrete Bonded Joints with FRP Sheet Anchor System
}

\author{
Weiwen Li $\left(\mathbb{D}\right.$, Wei Liu, Xu Yang $\mathbb{D}^{D}$, and Feng Xing \\ Guangdong Provincial Key Laboratory of Durability for Marine Civil Engineering, Shenzhen University, Shenzhen 518060, China \\ Correspondence should be addressed to Xu Yang; yangxu@szu.edu.cn
}

Received 2 September 2019; Revised 22 November 2019; Accepted 8 January 2020; Published 18 March 2020

Academic Editor: Guoqiang Xie

Copyright (c) 2020 Weiwen Li et al. This is an open access article distributed under the Creative Commons Attribution License, which permits unrestricted use, distribution, and reproduction in any medium, provided the original work is properly cited.

\begin{abstract}
Fiber-reinforced polymer (FRP) has been widely used for retrofitting and strengthening concrete structures over the past two decades. Because concrete members retrofitted by externally bonded FRP sheets can fail prematurely in debonding because of the fracture between FRP and concrete, FRP tensile strength cannot be fully utilized in engineering practices. Numerous useful investigations have been conducted to develop effective anchor systems to restrict FRP debonding. Thus, an FRP sheet-anchor system was developed and observed to be one of the most effective and convenient anchor systems. The FRP sheet-anchor system is applied to reinforced concrete beams strengthened with U-wrapping and side-bonded FRP configurations in few design guidelines. However, only a few investigations have focused on the failure mechanism of the FRP sheet-anchor system in the existing literature. Therefore, the main objective of this study is analyzing the effect of the carbon FRP (CFRP) sheet-anchor system on the bonding behavior of the CFRP-concrete interface, particularly the effect of the width and stiffness of the CFRP sheet-anchor system. In addition, the anchor-strengthened stage is defined by the load-slip response, which is different from that of specimens without the CFRP sheet-anchor system. Based on the experimental results, three linear stage models of the bond-slip constitutive relationship are proposed in this study.
\end{abstract}

\section{Introduction}

In reinforced concrete (RC) members, shear-strengthened with externally bonded fiber-reinforced polymer (FRP) sheets, the premature debonding failure mode often occurs in the side-bonding or U-wrapping FRP schemes. Such debonding can bring a few serious issues, not only because FRP composites cannot fully play out their high tensile performance but also because the strengthening member will suffer low efficiency and ductility.

Throughout the $21^{\text {st }}$ century, research on FRP strip debonding failure has accelerated, as various anchor systems have been devised and tested in academia and industry [1-5]. One anchorage system is the FRP spike anchor, which is made of a tow of unidirectional fibers to be inserted into the predrilled holes in concrete, which can be pushed through to the other end of the tow where this relatively new FRP spike anchor spreads on top of the FRP to form a fan [6-10]. These investigations have shown that this anchor system can improve the ultimate capacity [6] and can be used to prevent premature debonding of FRP sheets from concrete surfaces [7]. Llauradó et al. [8] presented an analytical model to predict the anchoring behavior of the FRP spike anchor system; Breña and Mcguirk [9] and Teng et al. [10] showed that the FRP spike anchor system can enhance both the capacity and ductility of FRP reinforced concrete members to some extent. Some metallic elements such as bolts and plates have also been used to anchor systems and have good applicability in improving capacity [11-16].

Another type of anchorage system is the FRP U-wrap anchor system, which refers to an FRP U-wrap sheet wherein the ends of the FRP sheet are vertically inserted to protect the reinforced member. It is a convenient and effective anchoring method used to delay and inhibit the premature 
debonding failure of FRP sheets and to improve the capacity and ductility of the components. It mainly includes the CFRP U-shaped laminate anchor system for flexural reinforcement [17-23] and the FRP U-jacking system for shear reinforcement [24-26]. Fu et al. [27] showed that both the load-carrying capacity and the ductility of an FRP-plated RC beam can be significantly enhanced by FRP U-wraps at the critical plate end. Lee [28] found two key factors which involves the externally bonded FRP system with the U-wrap. One is the stress concentration at the corner of the U-wrap, and the other is the frictional effect between the debonded surfaces under the region of the U-wrap after debonding. Lee and Lopez [29] found that the FRP U-wraps with a $45^{\circ}$ angle without an edge distance maximize the benefit of the anchoring effect after using U-wraps as an anchorage. Lee and Lopez [30] proposed a frictional bond-slip (FBS) model to analyze the behavior of the concrete-FRP interface region under the U-wrap and applied them in the numerical analysis. Leung [31] proposed that U-wraps can enhance the critical capacity and U-wraps should be inserted into cracks at the very beginning of their development. The experiments of Al-Mahaidi and Kalfat [32] showed that the FRP patch anchors could significantly improve the bond capacity of FRP. Kalfat et al. [33] provided an evaluation framework based on anchor efficiency which uses anchorage efficiency factors assigned to each anchor type for performance assessment and cross comparisons. They found out that the hybrid FRP anchor with patch was the most effective shear anchor types.

Existing experimental results have shown that above anchor systems can improve bond capacity and delay debonding of the FRP-concrete interface. However, these anchor systems have several limitations in practice. For example, FRP spike anchors, mechanical fasteners, and metallic rods all require predrilled holes in both the FRP sheet and concrete. Anchor systems with metallic elements are prone to corrosion. Different from the three-sided FRP U-wrap systems which are introduced in ACI 440.28-17 [34], the CFRP sheet anchor used in this experiment is bonded on only one side with less space limitations. However, the FRP sheet anchor system does not require this predrilling process. Therefore, the FRP sheet anchor system can be widely used because of its simple operation, easy construction, excellent corrosion resistance, and less occupied space. In few design guidelines, such as GB50608-2010 [35], the FRP sheet anchor system is recommended for RC members shear-strengthened with $\mathrm{U}$-wrapping and sidebonded FRP schemes.

However, despite continued interest in bond behavior of FRP-to-concrete interface [36], few investigations have considered the effect of the FRP sheet-anchor system on the bonding behavior of the FRP-concrete interface [25]. Those studies that do work with FRP U-wrap anchor sheets generally emphasize the improvement of their bonding capacity without considering the effect of their different widths and stiffness (determined by number of layers, also referred to as plies). This paper fills this information gap by providing an experimental investigation into the bonding behavior of the FRP-to-concrete interface with various FRP anchor sheet widths and plies using single shear tests. The main objectives of this experiment include finding out the most effective width and stiffness of CFRP sheet anchor, elaborating the failure mechanism of the FRP sheet-anchor system, and figuring out the bonding stress-slip relationship of FRP sheets with different anchoring conditions.

\section{Experimental Program}

2.1. Specimen Design. The near end supported (NES) single shear pull test serves as the setup for the experiment which can similarly imitate the stress state in the critical region of a crack-induced debonding failure beam. The dimensions of the concrete prisms were $400 \mathrm{~mm} \times 400 \mathrm{~mm} \times 100 \mathrm{~mm}$, and the width and bonding length of the FRP tensile sheet were $50 \mathrm{~mm}$ and $300 \mathrm{~mm}$, respectively, as shown in Figure 1. In addition, two layers (plies) of CFRP tensile sheets (i.e., the longitudinal CFRP sheet) were bonded layer by layer, and there was an unbonded region of $50 \mathrm{~mm}$ length from the edge of the concrete block near the loading end to avoid the wedge failure of concrete caused by the bonding stress concentration in the test. The effective bond length was about $129 \mathrm{~mm}$ calculated by the Chen and Teng anchorage strength model [37]. To keep the FRP anchor sheet from interfering with the effective bond length of the tensile sheet, all of the FRP anchor sheets were bonded out past the range of $150 \mathrm{~mm}$ length from the bonding area. The dimension details of the test specimen are shown in Figure 1.

Twenty-four FRP-to-concrete joints were cast and tested to failure in single shear approach, and every three specimens were repeated for each joint configuration to minimize the experiment accidental error. The main experiment parameters of the anchored joints consisted of (i) width of anchor sheets and (ii) stiffness or thickness of anchor sheets (defined as number of CFRP plies).

The anchored specimens are divided into two groups according to the test variables. The first group is set apart to investigate the effect of different widths of the anchor sheet on the single shear test. The width of the CFRP sheet anchor refers to the length of the area that the CFRP sheet anchor overlaps the longitudinal FRP sheet. The width of the anchor sheet $W_{a}$ in the first group is $1,1.5,2$, and 3 times the width of the FRP tensile sheets (i.e., $50 \mathrm{~mm}$, $75 \mathrm{~mm}, 100 \mathrm{~mm}$, and $150 \mathrm{~mm}$ ), respectively, with the same anchor sheet layers (i.e., two plies of the FRP sheet). The second group is designed to study the effect of different CFRP sheets based on the number of plies for stiffness or thickness as CFRP sheet anchor. The concrete mix was $425.8 \mathrm{~kg} / \mathrm{m}^{3}$ cement, $622.7 \mathrm{~kg} / \mathrm{m}^{3}$ sand, $1156.5 \mathrm{~kg} / \mathrm{m}^{3}$ stone, and $195 \mathrm{~kg} / \mathrm{m}^{3}$ water. The maximum aggregate size was $25 \mathrm{~mm}$. The type of cement was 32.5 ordinary Portland cement (OPC). In this group of specimens, the layer(s) of CFRP sheet anchor $L_{a}$ is selected to be $0.5,1$, 1.5 , and 2 times (i.e., $1,2,3$, and 4 plies) the layered sheet anchor of FRP tensile sheets, respectively, while the width of all anchor sheets remained $100 \mathrm{~mm}$. The details of specimens are shown in Table 1. 


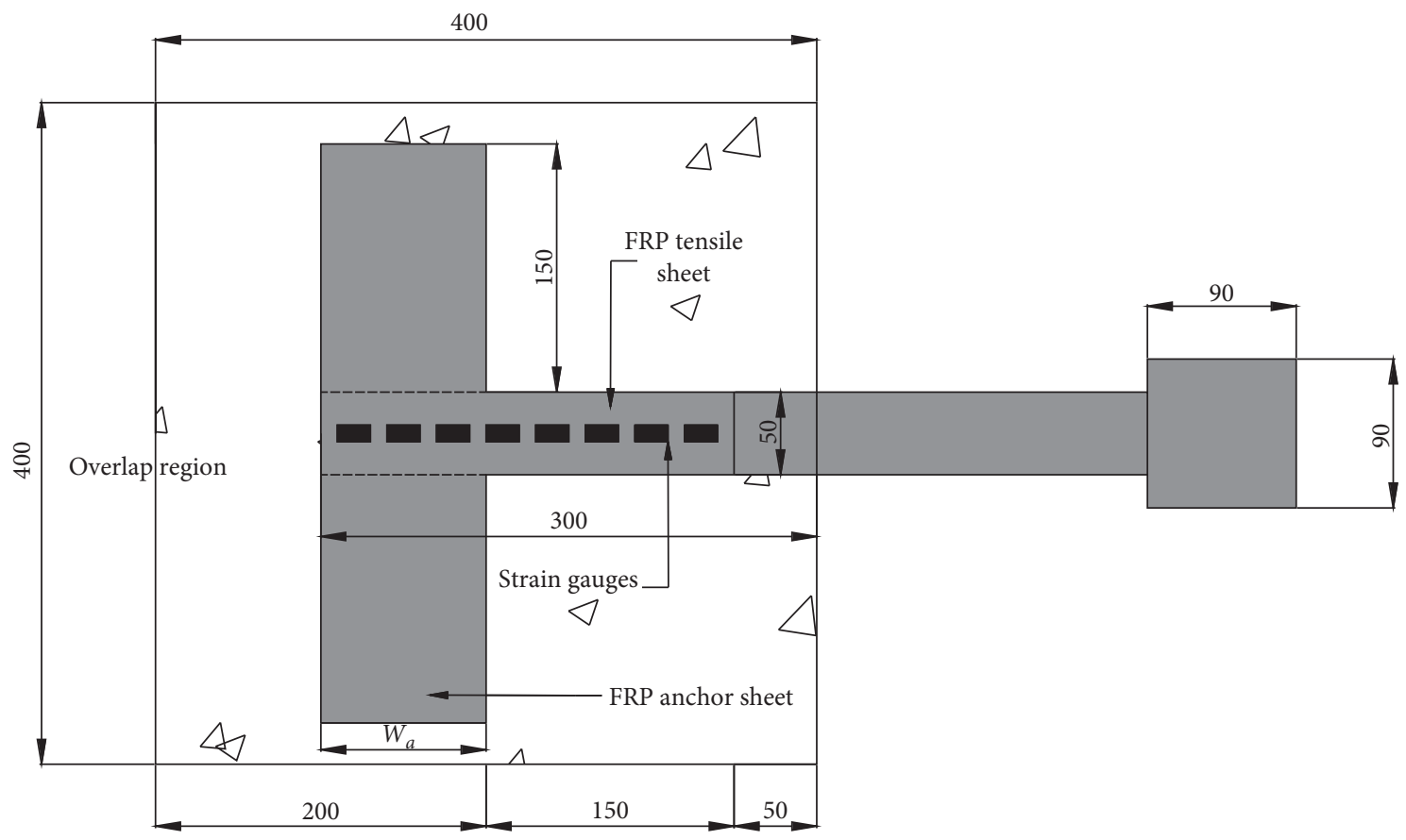

FIGURE 1: Detailed dimensions of the test specimen (unit: $\mathrm{mm}$ ).

TABle 1: Specimen parameters.

\begin{tabular}{lccc}
\hline Specimen & $W_{a}(\mathrm{~mm})$ & $L_{a}$ (layer) & Quantity of specimens \\
\hline W0L0-1/2/3 & 0 & 0 & 3 \\
W50-1/2/3 & 50 & 2 & 3 \\
W75-1/2/3 & 75 & 2 & 3 \\
W100 (L2)-1/2/3 & 100 & 2 & 3 \\
W150-1/2/3 & 150 & 2 & 3 \\
L1-1/2/3 & 100 & 1 & 3 \\
L3-1/2/3 & 100 & 3 & 3 \\
L4-1/2/3 & 100 & 4 & 3 \\
\hline
\end{tabular}

${ }^{*}$ Note. $W_{a}$ represents the CFRP sheet anchor width and $L_{a}$ represents the number of CFRP sheet anchor layers or plies. The number in the last part of the specimen name refers to the replication number (three of each specimen type).

2.2. Material Properties. The concrete used in this study was mixed in the lab with a designed compressive strength of $30 \mathrm{MPa}$ determined by the $150 \mathrm{~mm} \times 150 \mathrm{~mm} \times 150 \mathrm{~mm}$ cube specimens. The average cube compressive strength of concrete at 28 days was $27.1 \mathrm{MPa}$. The nominal thickness of the CFRP sheet anchor was $0.167 \mathrm{~mm}$. The average test tensile strength and tensile modulus of the CFRP sheet anchor were $3,499 \mathrm{MPa}$ and $273 \mathrm{GPa}$, respectively. Meanwhile, the tensile strength and elastic modulus of the epoxy resin were $44 \mathrm{MPa}$ and 2,600 $\mathrm{MPa}$, respectively. The shear strength of epoxy resin is $17 \mathrm{MPa}$. The epoxy used in the experiment was commercially bought from the local company in mainland China. The material properties are summarized in Table 2.

2.3. Test Program. The test setup included a steel frame, which consisted of four steel bars (20 $\mathrm{mm}$ diameter) and two steel plates (20 mm thickness). The CFRP sheet crossing the square hole in the steel plates was applied with a tensile load by a universal testing machine through the gripped CFRP plate in the end. The test setup is shown in Figure 2, and the capacity of the tension load-cell is $100 \mathrm{kN}$. The type of strain gauge used in the experiment is the electrical resistance strain gauge, and the loading rate was $0.15 \mathrm{~mm} / \mathrm{min}$. During testing, the strain and load values were recorded at a frequency of $1 \mathrm{~Hz}$, and the load was applied at a rate of $0.15 \mathrm{~mm} / \mathrm{min}$. All specimens were preloaded to $2 \mathrm{kN}$ first to check if the eccentric effect was present during the test.

\section{Experimental Results and Analysis}

3.1. Failure Mode. In the NES single-shear pull test of the FRP-concrete interface, the debonding of FRP sheets was caused by the cracking of the concrete surface, namely, failure in the substrate concrete. Different failure modes were observed during the test, which were related to the FRP anchor sheet configuration. Moreover, the longitudinal tensile FRP sheet failed in different ways compared to the CFRP sheet anchor in the same specimen.

The control specimens (W0L0) failed as expected as the debonding failure originated at the loaded end and propagated toward the free end [41]. Most longitudinal CFRP sheets failed by concrete debonding with concrete attached to the CFRP sheet. However, the failure of the L4 group occurred when the longitudinal CFRP sheet ruptured at the junction of the overlap area. The probable reason was that the large anchor force provided by the high stiffness of the 4ply CFRP sheet anchor restrained the debonding of the longitudinal CFRP sheet in the free end. At same time, the tensile force mainly concentrated at the edge of the CFRP sheet anchor due to the limited slip of this part. Finally, the tensile force exceeded the tensile strength of the longitudinal 
TABLE 2: Material property information.

\begin{tabular}{|c|c|c|c|}
\hline Material & Property & Value (MPa) & Standard \\
\hline & 28-day cube compressive strength & 27.1 & \multirow{2}{*}{ GB/T 50081-2002 [38] } \\
\hline Concrete & Test day cube compressive strength & 37.7 & \\
\hline CFRP & $\begin{array}{c}\text { Tensile strength } \\
\text { Modulus }\end{array}$ & $\begin{array}{c}3499 \\
273000\end{array}$ & GB/T 3354-1999 [39] \\
\hline Epoxy & $\begin{array}{l}\text { Tensile strength } \\
\text { Modulus }\end{array}$ & $\begin{array}{c}44 \\
2600\end{array}$ & $*$ \\
\hline
\end{tabular}

Note. ${ }^{*}$ means the data were provided by the manufacturer [40].

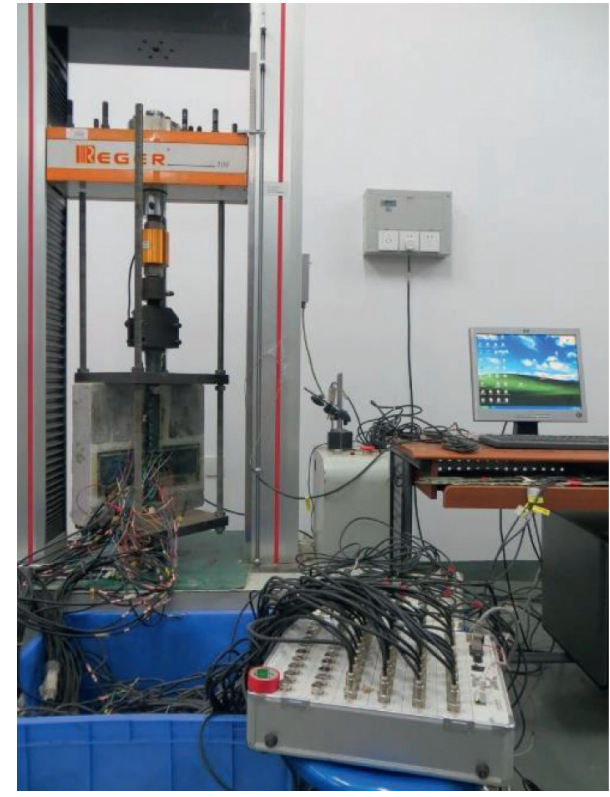

Figure 2: Test setup for single shear test.

CFRP sheet causing rupture to occur. The failure modes of the CFRP sheet anchor could be divided into three kinds, namely, debonding at the adhesive-concrete interface, the CFRP sheet anchor rupture, and debonding with the concrete. Some of the specimens' failure modes are shown in Figure 3, and all the specimens' failure modes are reported in Table 2. Section 3.3 will discuss the failure mechanism of the longitudinal CFRP sheet and CFRP sheet anchor.

3.2. Ultimate Capacity. The ultimate load is one of the most important parameters used to evaluate the interface bonding performance. According to the experiment results, the improvement of the ultimate load with different widths and layers of the CFRP sheet anchor was analyzed. Table 2 shows that increasing the width of the CFRP sheet anchor can improve ultimate load to some extent, but it is limited by the CFRP sheet width and layers. Experimental results show that the maximum load was achieved when the width of the CFRP sheet anchor was about 2 times (i.e., $100 \mathrm{~mm}$ ) wider than the tensile CFRP sheet. Moreover, the load increase improved by the unit width of the CFRP sheet anchor did not always increase as the width of the anchor sheet increased. For example, when the width of the CFRP sheet anchor increased from $50 \mathrm{~mm}$ to $75 \mathrm{~mm}$, the increase of ultimate load improved per unit as the width of each CFRP sheet anchor increased from $2.0 \mathrm{kN}$ to $3.3 \mathrm{kN}$ (as shown in Table 2). While the width of the CFRP sheet anchor continues to increase from $75 \mathrm{~mm}$ to $150 \mathrm{~mm}$, the increase of the ultimate load improved per unit as the width of the CFRP sheet anchor dropped from $3.3 \mathrm{kN}$ to $1.9 \mathrm{kN}$ (as shown in Table 2).

The increase in the CFRP sheet anchor stiffness (number of plies) can cause the ultimate load to increase almost linearly. When the number of the CFRP sheet anchor layers increases from 1 to 2 layers, the increase of the ultimate load by the unit stiffness of the CFRP sheet anchor increases from $5.8 \mathrm{kN}$ to $6.3 \mathrm{kN}$ (as shown in Table 2). However, when the layers continue to increase from 2 to 4 layers, the improvement of the ultimate load by unit stiffness of the CFRP sheet anchor remains at about $6.0 \mathrm{kN}$, which means that when the layer width of the CFRP sheet anchor is 2 times greater than the layer of the longitudinal CFRP sheet, the utilization rate of the CFRP sheet anchor reaches the maximum value. When layers of the CFRP sheet anchor increases, the thickness of the tensile sheet increases to some extent, which increases the ultimate capacity of FRP-toconcrete surface bonding area. However, the rigidity of overlap area also increases and will eventually cause stress concentration at the junction, leading to a premature destruction of the longitudinal CFRP sheet. Thus, the number of layers in the CFRP sheet anchor also increases the final capacity within a certain range as shown in Table 3.

Generally speaking, from the results of this test, the enhanced bonding behavior between the longitudinal CFRP sheets and the concrete due to the anchoring effect of the CFRP sheet anchor gave a good performance, and the utilization rate of the CFRP sheet anchor obtained their greatest value when the CFRP sheet anchor was 1.5 times the tensile CFRP sheet width and the CFRP sheet anchor was two times its length. Furthermore, increasing the number of plies to 3 or 4 in the CFRP sheet anchor or doubling their length is more effective than increasing their width. It is recommended that in practical engineering design, the former choice should be given priority.

3.3. Failure Mechanism. The role of the CFRP sheet anchor can be summarized as having two functions: providing confining stress to the interface between the concrete and FRP sheet which was mainly functioned at the overlap crosssectional areas and enhancing an anchoring effect with friction which is exerted at the debonded cross-sectional 


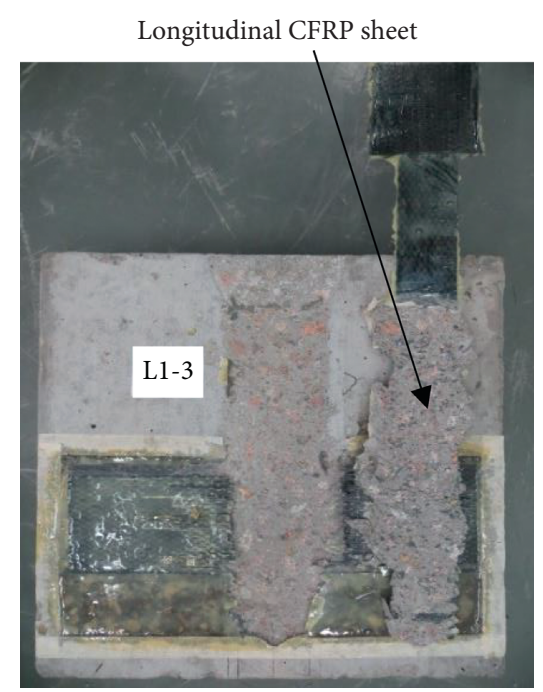

(a)

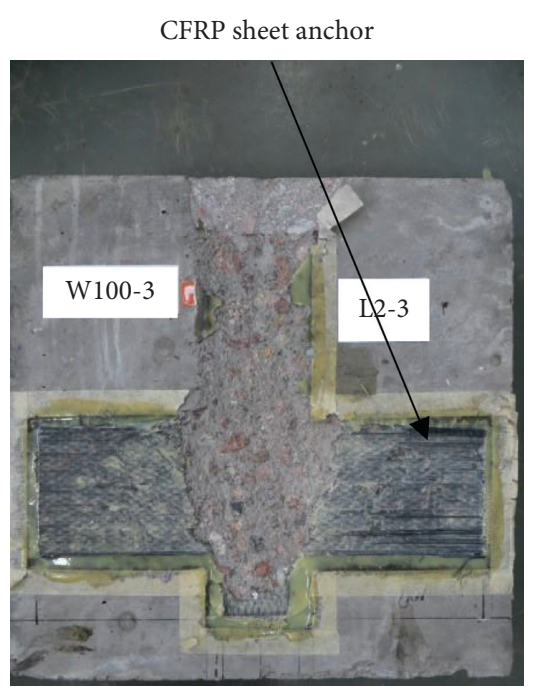

(b)

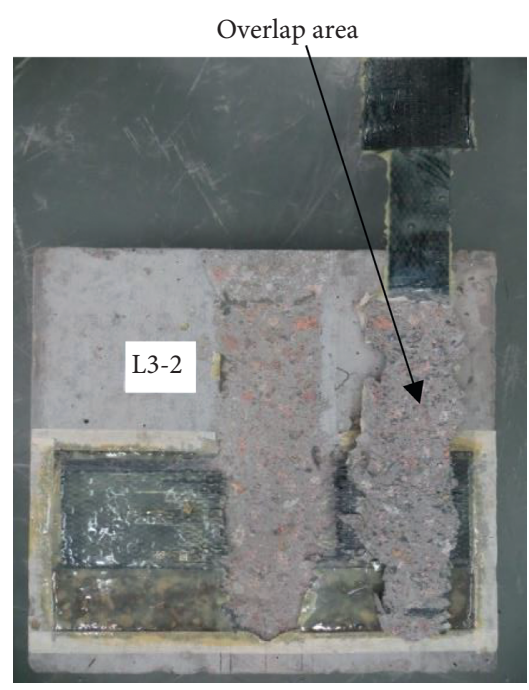

(c)

FIgURE 3: Failure modes of longitudinal CFRP sheet and the CFRP sheet anchor. (a) L1-3. (b) L2-3. (c) L3-2.

TABLE 3: Ultimate bearing capacities of test specimens.

\begin{tabular}{|c|c|c|c|c|c|c|}
\hline Specimens & $\begin{array}{c}\text { Ultimate load } \\
(\mathrm{kN})\end{array}$ & Failure mode & $\begin{array}{c}\text { Average load } \\
(\mathrm{kN})\end{array}$ & $\begin{array}{c}\text { Increased load } \\
(\mathrm{kN})\end{array}$ & $\begin{array}{c}\text { Increased ratio } \\
(\%)\end{array}$ & $\begin{array}{l}\text { Unit load increased value } \\
\qquad(\mathrm{kN})\end{array}$ \\
\hline W0L0-1 & 27.3 & SD & & & & \\
\hline WOLO-2 & 31.5 & SD & 29.2 & - & - & - \\
\hline W0L0-3 & 28.7 & SD & & & & \\
\hline W50-1 & 30.8 & $\mathrm{SD}, \mathrm{SAD}$ & & & & \\
\hline W50-2 & 30.6 & $\mathrm{SD}, \mathrm{SAD}$ & 31.2 & 2 & 6.85 & 2 \\
\hline W50-3 & 32.1 & $\mathrm{SD}, \mathrm{SAD}$ & & & & \\
\hline W75-1 & 33.5 & $\mathrm{SD}, \mathrm{SAD}$ & & & & \\
\hline W75-2 & 34.2 & SD, SAD & 34.1 & 4.9 & 16.78 & 3.3 \\
\hline W75-3 & 34.5 & $\mathrm{SD}, \mathrm{SAD}$ & & & & \\
\hline W100 (L2)-1 & 33.3 & $\mathrm{SD}, \mathrm{SAD}$ & & & & \\
\hline W100 (L2)-2 & 36.3 & $\mathrm{SD}, \mathrm{SAD}$ & 35.5 & 6.3 & 21.58 & $3.2(6.3)^{*}$ \\
\hline W100 (L2)-3 & 36.9 & $\mathrm{SD}, \mathrm{SAD}$ & & & & \\
\hline W150-1 & 34.7 & $\mathrm{SD}, \mathrm{AD}$ & & & & \\
\hline W150-2 & 35 & $\mathrm{SD}, \mathrm{AD}$ & 35 & 5.8 & 19.86 & 1.9 \\
\hline W150-3 & 35.2 & $\mathrm{SD}, \mathrm{AD}$ & & & & \\
\hline L1-1 & 29.4 & $\mathrm{SD}, \mathrm{SAD}$ & & & & \\
\hline L1-2 & 35.3 & SD, SAD & 32.1 & 2.9 & 9.93 & 5.8 \\
\hline $\mathrm{L} 1-3$ & 31.7 & $\mathrm{SD}, \mathrm{SAD}$ & & & & \\
\hline L3-1 & 38 & $\mathrm{SD}, \mathrm{AD}$ & & & & \\
\hline L3-2 & 35.4 & $\mathrm{SD}, \mathrm{AD}$ & 37.7 & 8.5 & 29.11 & 5.7 \\
\hline L3-3 & 39.7 & $\mathrm{SD}, \mathrm{AD}$ & & & & \\
\hline L4-1 & 42.7 & $\mathrm{SD}, \mathrm{AD}$ & & & & \\
\hline L4-2 & 37.8 & $\mathrm{SD}, \mathrm{AD}$ & 41.3 & 12.1 & 41.44 & 6.1 \\
\hline L4-3 & 43.3 & $\mathrm{SD}, \mathrm{AD}$ & & & & \\
\hline
\end{tabular}

Note. $W$ series: unit load increased value $=$ increased load $/\left(W_{a} / W_{t}\right)$ and $L$ series: unit load increased value $=$ increased load $/\left(L_{a} / L_{t}\right)$, where $W_{a}-$ the width of the CFRP sheet anchor; $W_{t}$-the width of the tensile sheet; $L_{a}$-the number of the CFRP sheet anchor layers; and $L_{t}-$ the number of the longitudinal CFRP sheet. * The unit load increased value of the W100 series was $3.2 \mathrm{kN}$. The unit load increased value of the L2 series was $6.3 \mathrm{kN}$. SD = sheet debonding; SR $=$ sheet rupture; $\mathrm{SAD}=$ delamination between sheet and anchor sheet; $\mathrm{AD}=$ anchor sheet debonding.

areas along the whole length of longitudinal CFRP sheet. The stress transfer mechanism between CFRP tensile sheets and concrete is described as follows. At the initial elastic stage of the loading process, the load transferred from the CFRP tensile sheets to the concrete through the epoxy resin and the concrete interface remains intact. With the gradual increase of loading, when the interface fracture energy reached a critical value, the initial debonding occurred and microcracks of concrete formed beneath the interface with bonding stress gradually stretched to the free end. As for the 
longitudinal FRP sheet without the CFRP sheet anchor, the debonding failure was transient and brittle because there was no confinement effect.

Some differences can be found in the failure phenomenon of the CFRP anchor sheet: as discussed and found out by Lee $[29,30]$, the role of the CFRP sheet wrap includes both providing confining stress to the interface between the concrete and FRP sheet (before debonding) and an anchoring effect with friction (after debonding). The peeling off of the overlap area on the concrete interface was larger and rougher than that on the nonoverlap section. Reasons explaining these results begin with the CFRP sheet anchor's increased thickness and rigidity in the overlap area, which increased the reaction force of the substrate concrete under the overlap area. Thus, the occlusal force between the concrete coarse aggregates in the overlap zone was enhanced. The reaction stress from the CFRP sheet anchor acts upon the interface, resulting in an increased onset of debonding stress. When the debonding started extending into the overlap area of the longitudinal CFRP sheet, the concrete under the overlap area endured a dragging and pulling effect from both the longitudinal CFRP sheet and the CFRP sheet anchor. The concrete under the nonoverlap area of CFRP sheet anchor bore the tensile strength only from the longitudinal CFRP sheet which was much smaller.

The increased strain of CFRP sheet anchor due to the increased slip generates the larger reaction stress acting on the interface between the two debonded surfaces. Therefore, the adhesive concrete volume was much larger and the concrete's debonding surface was rougher. Then, when the debonding occurred, the CFRP sheet anchor was staggered into a "V" shape along the tensile sheet direction due to the pulling effect of longitudinal CFRP sheet. The force provided by the CFRP sheet anchor could be divided into two directions. One of the components was the pulling force along the original fiber's downward direction which provided a tensile force on the longitudinal CFRP sheets in the CFRP sheet anchor cross-sectional areas as shown in Figure 4(a). The other component force was along the vertical direction of the original fibers of the CFRP sheet anchor. Because the CFRP sheet anchor is a unidirectional material, the components along the vertical direction of the original fibers were resisted by the epoxy resin layer, but the strength provided by epoxy resin layer was limited; thus, the pull force in the oblique downward direction contributed the most to the anchoring effect which resulted in local rupture failure and finally caused the whole anchor sheet's layers of sheet anchor to be damaged. As shown in Figure 4, the anchoring mechanism of FRP sheet-anchorage system was vividly reflected by this illustration.

3.4. CFRP Strain Distributions. CFRP elongation along the length of the sheet is reported in Figures $5(\mathrm{a})-5(\mathrm{~g})$ for the unanchored and anchored specimens of different configurations. The control specimen failed at the maximum strain around $8000 \mu \varepsilon$ through cover separation failure. Partial delamination had occurred in the zones closest the loaded face when bond stress was transferred to the free edge of the concrete block because the strain distribution was observed to be uniform along the length of the sheet prior to failure. However, as for the FRP sheet anchoring specimens, the maximum strain increased from $8500 \mu \varepsilon$ to $10000 \mu \varepsilon$. In addition, a transfer of bond stress to a greater distance away from the loaded edge was observed throughout Figures 5(b)-5(g). The higher level of strain was recorded at a distance of $100 \mathrm{~mm}$ to $160 \mathrm{~mm}$ away from the loaded face while this value was around $100 \mathrm{~mm}$ for the unanchored specimens. The effective anchorage length was increased because of the FRP sheet anchor systems.

3.5. CFRP-Concrete Interface Load-Slip Curve. The load-slip curve reflects the corresponding relationship between the applied load and the slip of the longitudinal CFRP sheet at different load levels during the loading process. The test load was collected at the frequency of $1 \mathrm{~Hz}$ through the universal testing machine data acquisition system, and slip data were obtained by means of strain gauge value integration [42]. The typical test load-slip curves are shown in Figure 6.

For the specimens without FRP sheet anchor (i.e., specimen WOL0), because the bond length of the longitudinal CFRP sheet was greater than the effective bond length, the shear stress could be transferred from the loaded end to the free end fully as debonding developed. During this stage, the applied load could not increase anymore while the slip continued to increase which was shown as the horizontal region in Figure 6. The load-slip and simplified ideal curve obtained from the test results is shown in Figure 7 . The transverse axis of the figure is represented by the slip, and the longitudinal axis represents the applied load. The curve can be divided into the following four stages:

(1) The elastic stage ( $\mathrm{AB}$ as shown in Figure 7): this is the elastic stage of the load-slip curve at the beginning. The load increased rapidly from $0 \mathrm{kN}$ to around $15 \mathrm{kN}$ while the slip increased to about $0.1 \mathrm{~mm}$. FRP sheet, the resin adhesive layer, and concrete surface are all in the elastic state, and the interface does not show any obvious interface microcracks. It should be noted that the end of elastic stage was only related to the initial damage of the system within the range of the effective length; thus, the load level of ending is constant for all anchorage specimens. The effect of CFRP sheet anchor was very little on this value. At this time, all of these materials can be restored to their original state if the external force is unloaded.

(2) The softening stage (BC as shown in Figure 7): in this stage, the load increases gradually as the slip increases in a nonlinear relationship. When the load increases to a critical value, an inflection point occurs in the load-slip curve of around $15 \mathrm{kN}$ in this experiment and microcracks begin to appear at the FRP-concrete interface. More and more cracks form as the load further increases, causing the concrete at the interface to begin to peel. Point B corresponds to the initial softening point. In this stage, irreversible plastic deformation occurs in some areas. If the 


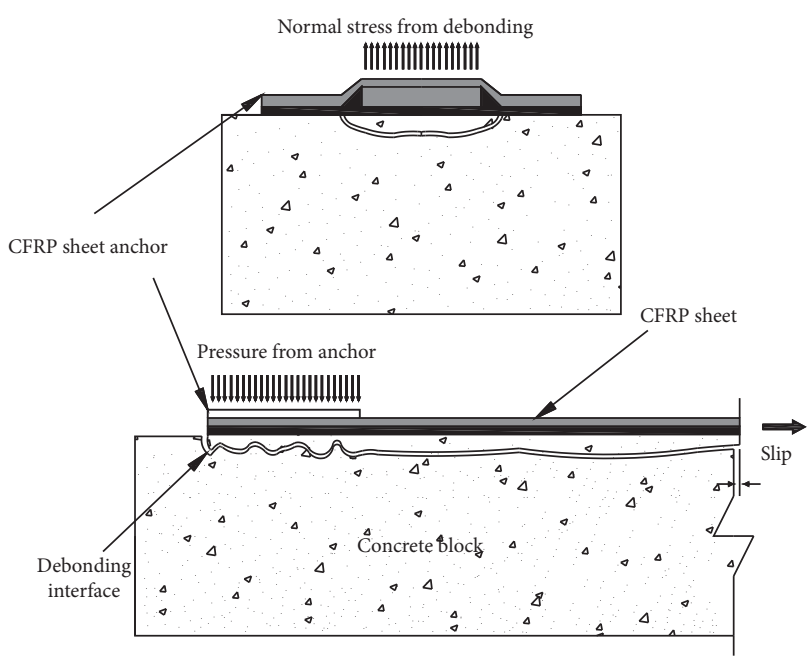

(a)

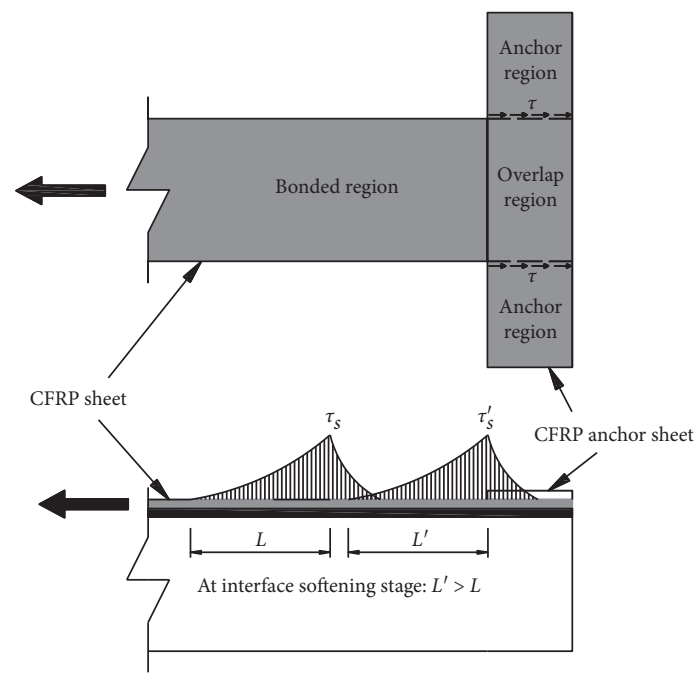

(b)

FIGURE 4: Anchoring mechanism of FRP sheet-anchorage system. (a) Sketch of anchoring mechanism. (b) Increased friction between two debonded surfaces.
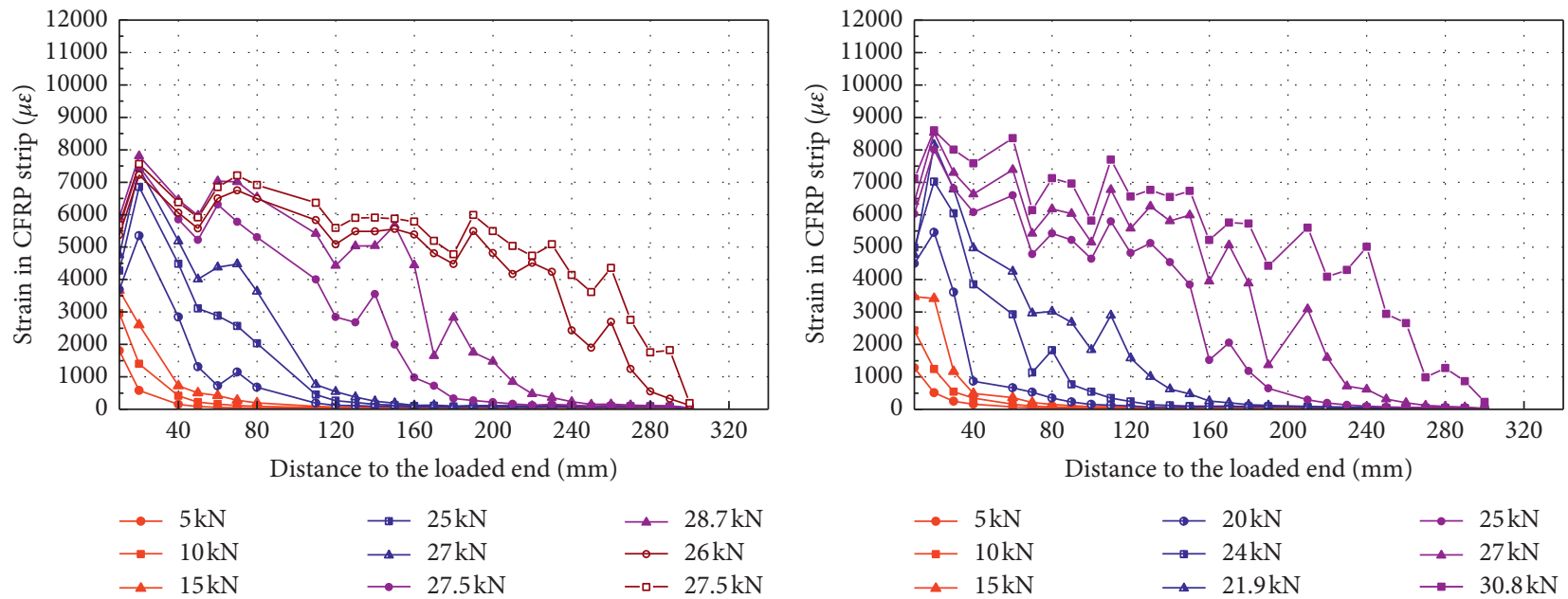

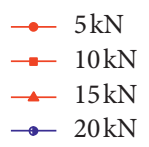

$\rightarrow 25 \mathrm{kN}$

$\rightarrow 27 \mathrm{kN}$

$\rightarrow 27.5 \mathrm{kN}$

(a)

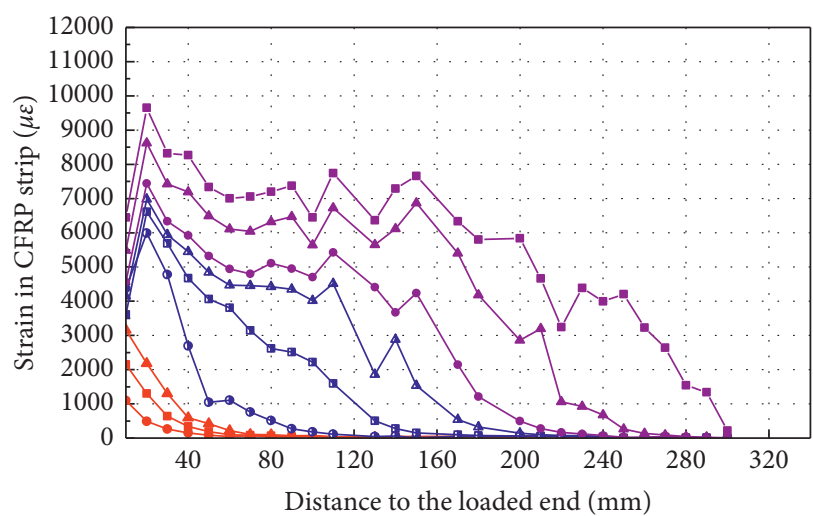

$\simeq 28.7 \mathrm{kN}$

$\rightarrow 26 \mathrm{kN}$

$-\mathrm{a}-27.5 \mathrm{kN}$ $\simeq 15 \mathrm{kN}$

(b)

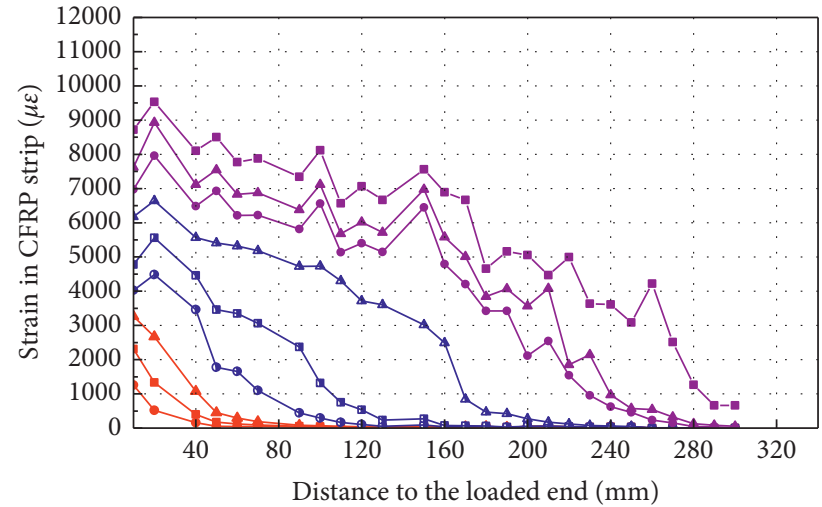

$\longrightarrow 5 \mathrm{kN}$
$\rightarrow 10 \mathrm{kN}$
$\simeq 15 \mathrm{kN}$

$\rightarrow 20 \mathrm{kN}$

$\rightarrow 22 \mathrm{kN}$

$\rightarrow 28 \mathrm{kN}$

$\because 10 \mathrm{kN}$

$\rightarrow 22 \mathrm{kN}$

$--34.5 \mathrm{kN}$

(c) (d)

Figure 5: Continued. 

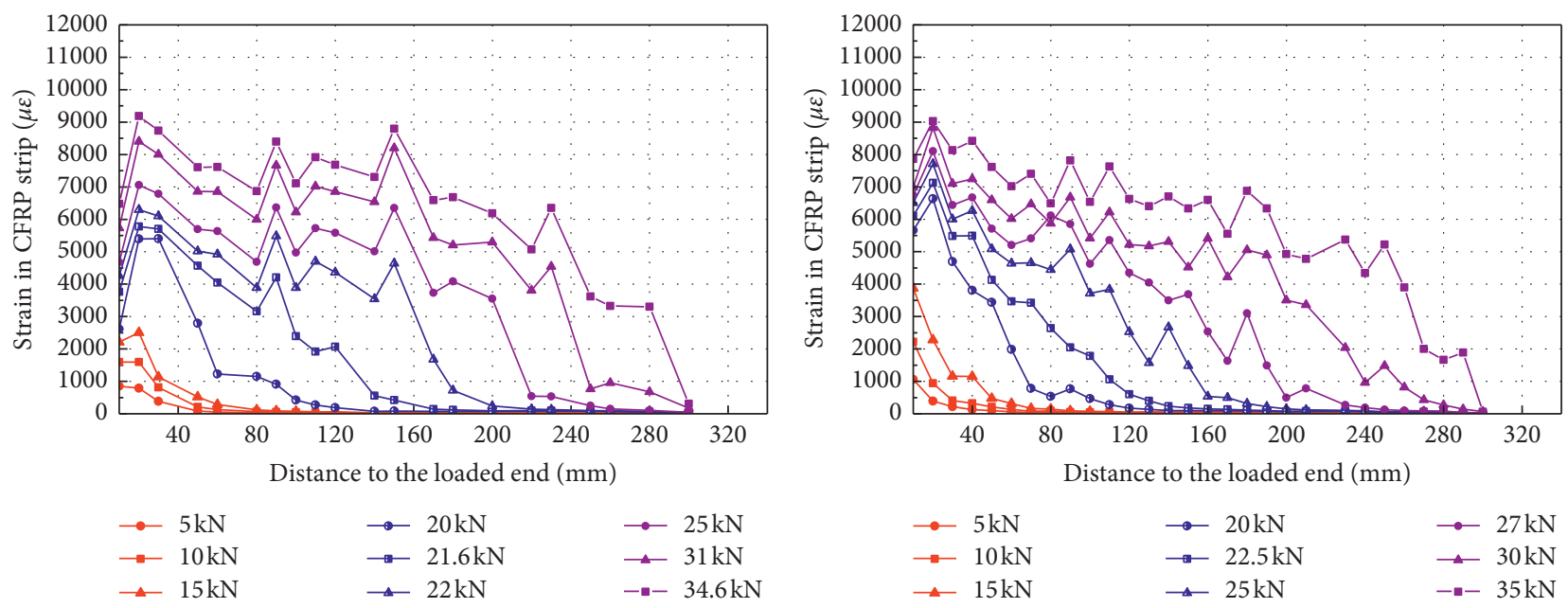

(e)

(f)

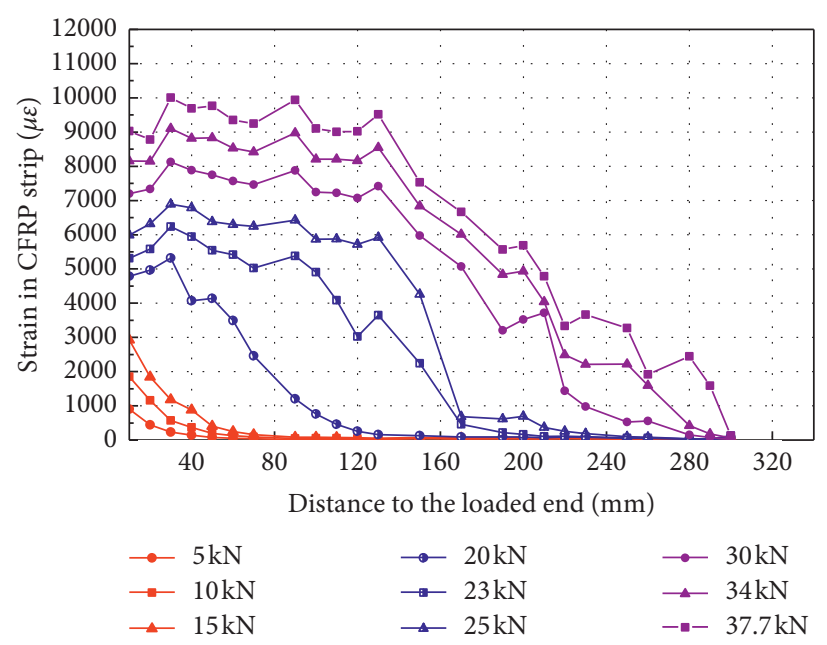

(g)

FIGURE 5: Strain vs distance along sheet: (a) W0L0-3; (b) W50-1; (c) W75-2; (d) W100-2 (L2-2); (e) W150-2; (f) L1-2; (g) L3-1.

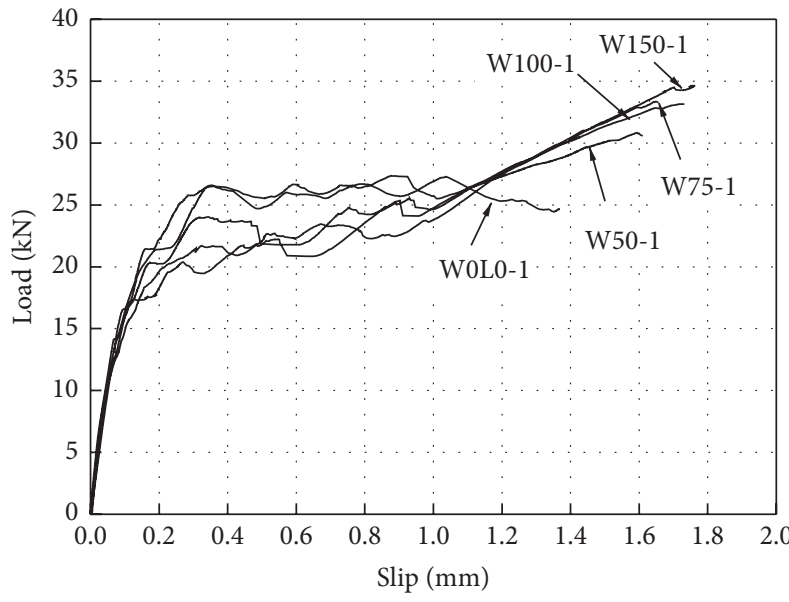

(a)

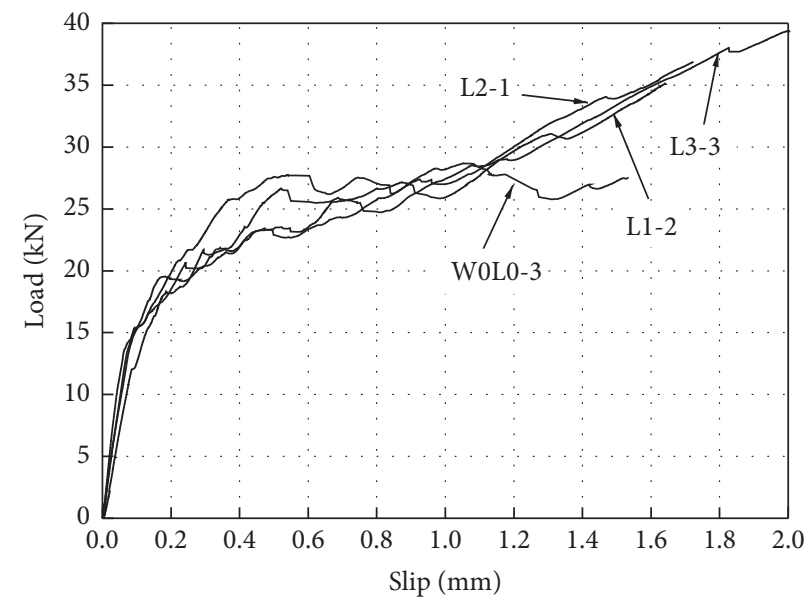

(b)

FIgURE 6: Experimental load-slip curves of specimens. (a) $W$ series and control specimens. (b) $L$ series and control specimens. 


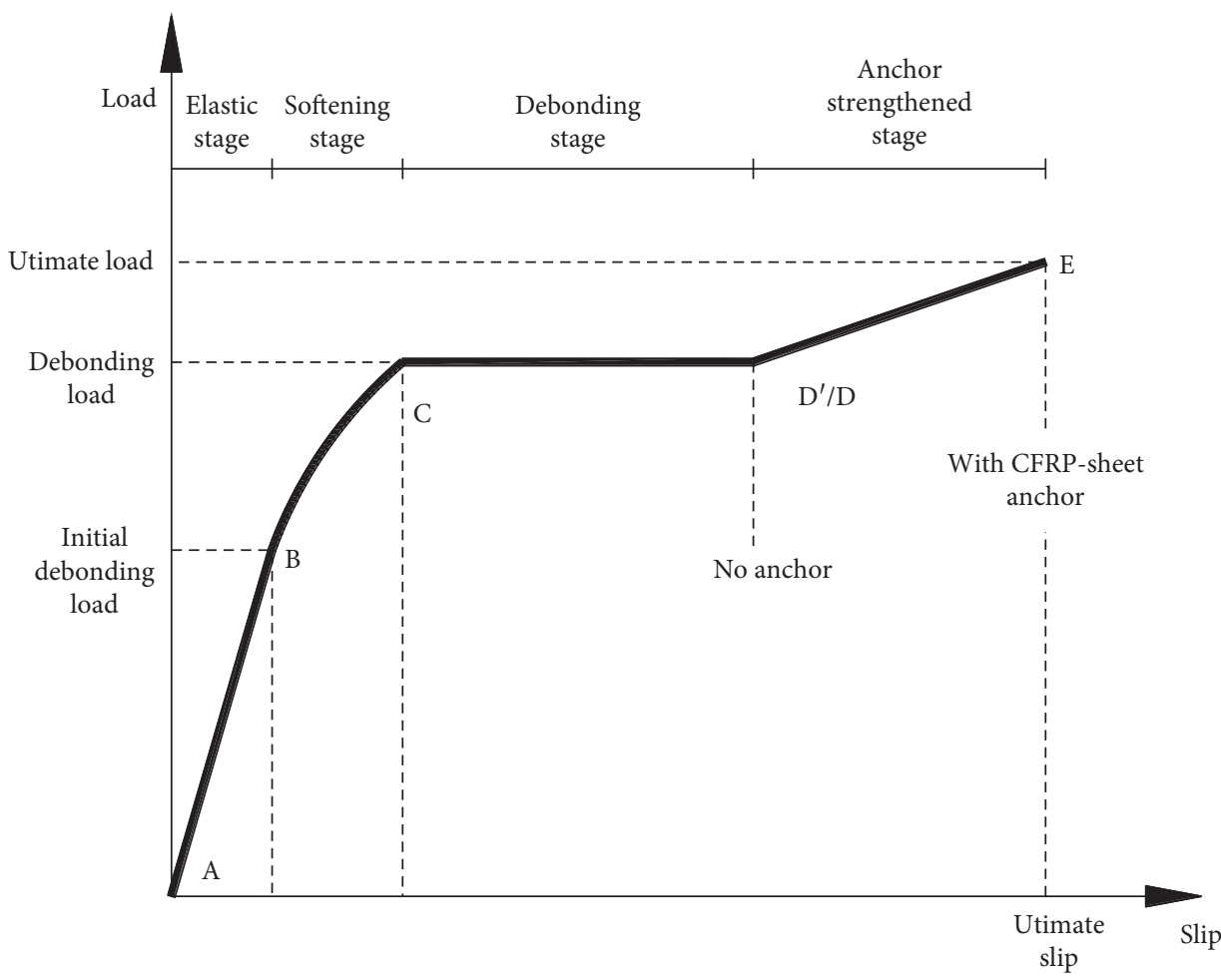

FIgURE 7: Theoretical load-slip curve of no anchor and anchorage specimens.

external force is unloaded, the interface material cannot be restored to the initial state. At this stage, the curves of the anchored and unanchored specimens are basically the same.

(3) The sliding stage ( $\mathrm{CD}^{\prime} / \mathrm{CD}$ as shown in Figure 7$)$ : at this stage, the curve is an almost horizontal line, which means that the load hardly increases while the slip increases rapidly. When the curve reaches the ultimate softening point (Point $\mathrm{C}$ ), the fracture of the concrete at the interface occurs and the debonding begins to gradually extend from the loading end toward the free end. Bonding stress begins to drop in the peeled area and the energy is released, while bonding stress in the nonpeeled area increases and the energy accumulates. In this stage, the load fluctuates in a small amplitude with the slip increases. As the interface concrete fractures from the load end to the free end, the effective bonding length of FRP is activated in different parts of the interface according to the debonding location of concrete. During this substitution process, the load instantly drops a little with the concrete near the load end fracturing while reversing to the normal load level as the effective stressed area stretches to the free end. The slip reaches its maximum value until the longitudinal CFRP sheet completely debonds without the CFRP anchor.

(4) The anchor strengthened stage (DE as shown in Figure 7): this phase only occurs in the FRP sheetanchored specimens. When the debonding of the longitudinal FRP sheets extends to the overlap area (i.e., the effective bonding length transfers to the anchored area), the load rises again due to the confinement stress and increased friction caused by the anchoring effect of the CFRP sheet anchor until the CFRP sheet anchor ruptures or fully detaches from the concrete. When the configuration (width or stiffness) of CFRP sheet anchor is changed, the ultimate load and slip will alter to some extent. As AlMahaidi and Kalfat [32] pointed out, CFRP anchorage systems have the effective bond length, which affects the bonding strength. When the layers of the CFRP sheet anchor are changed in this experiment from 1 to 4 layers, the corresponding load increases from $2.9 \mathrm{kN}$ to $12.1 \mathrm{kN}$. In this stage, although the load increase varies with the different CFRP sheet anchor configurations, the general appearance of the curve remains basically the same.

However, it should be noted that the FRP anchor sheet used in this experiment is different from the U-wrap anchors which were investigated by Lee and Lopez [28-30]. In Lee and Lopez's research [29], FRP U-wraps are typically externally bonded to the lateral sides and top faces of the concrete block. In our research, CFRP fabric was not wrapped around the curved edges of the block and did not bond a length down the sides of the concrete block. The stiffness of the overlap region in our study is thus significantly lower than that in the CFRP U-wrap anchoring specimens. This difference was probably the main reason that causes the different shapes of load-slip curves. Because in Lee and Lopez's research [29], the DE stage is considered as plateau behavior which means the CFRP U-wrap sheets 


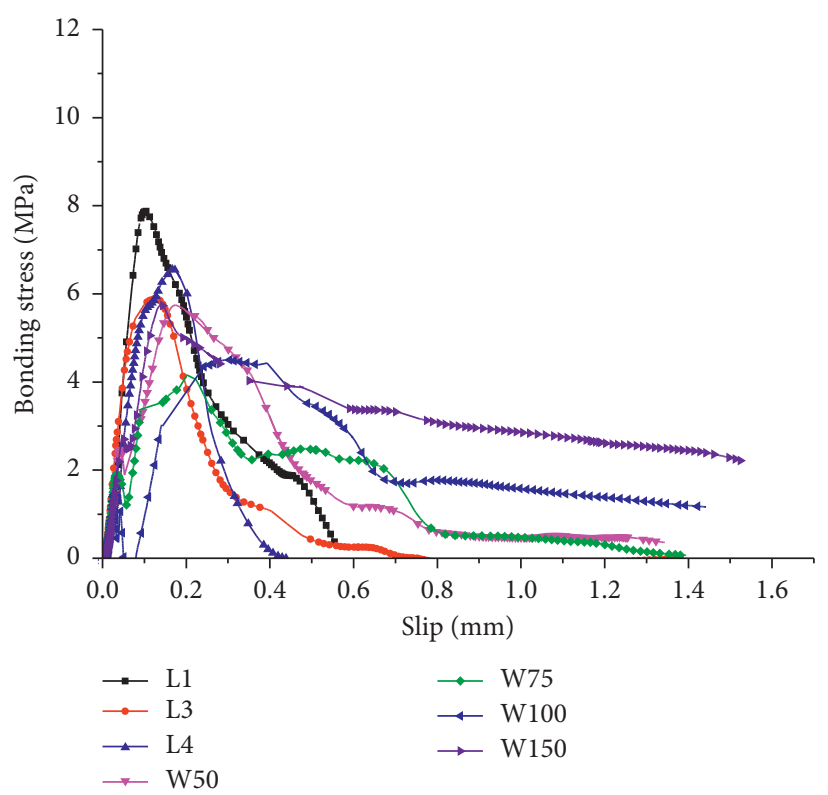

(a)

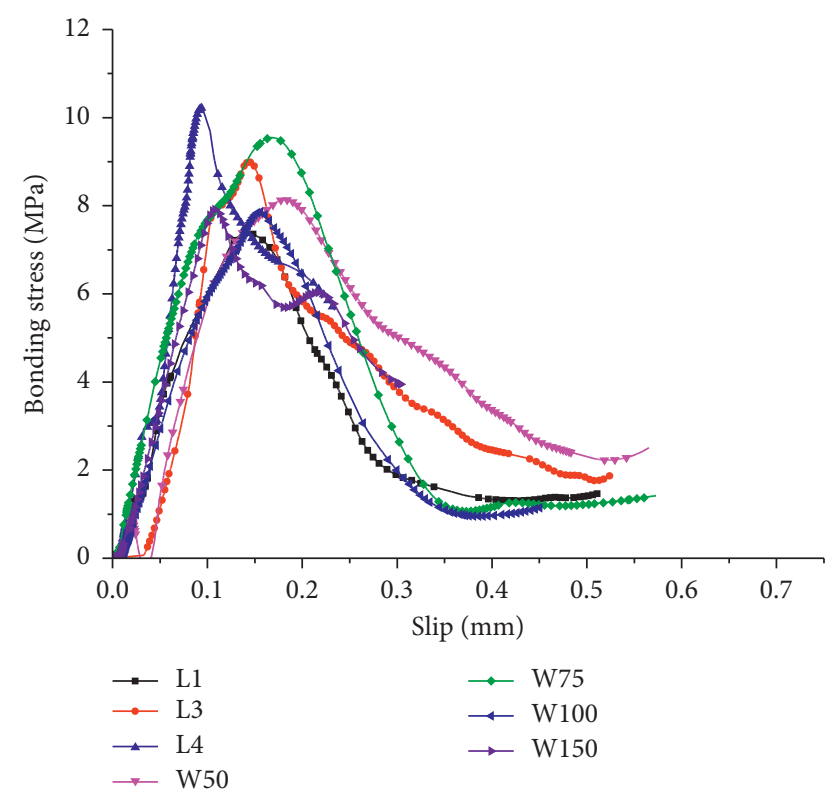

(b)

Figure 8: Bonding stress-slip curve of the (a) nonanchored area and (b) anchored area.

contribute to the bond strength at the BC stage in this study while for the lower stiffness of the CFRP sheet anchor, their function begins to take effect at the DE stage. More experiment investigation needs to be done to verify it.

In summary, the load-slip curves of the nonanchor specimens and the anchor specimens both include the elastic stage, the softening stage, and the sliding stage. However, the anchor specimen has another anchor strengthened stage, and the final state of the curve in the anchor strengthened stage is related to the configuration of the CFRP sheet anchor.

\section{Bonding Stress-Slip Curve}

The specimens' bonding performance significantly depends on the bonding stress-slip constitutive model of the interface. Considering the elastic behavior of the composite, the average value of shear stress between two subsequent strain gauges can be written as a function of the difference of measured strains, $\varepsilon_{i}$ and $\varepsilon_{i+1}$, which can be expressed as

$$
\tau_{i+1 / 2}=-\frac{E_{p} A_{p}\left(\varepsilon_{i+1}-\varepsilon_{i}\right)}{b_{p}\left(x_{i+1}-x_{i}\right)},
$$

where $A_{p}, b_{p}$, and $E_{p}$ stand for area, width, and elastic modulus of FRP sheet, and the slip is obtained by means of strain gauge value integration [42]. According to the analysis of the tested data, the bonding stress-slip curve at the overlapped area of the anchor specimen is obviously different from the nonoverlap zone, as shown in Figures 8(a) and $8(\mathrm{~b})$. The monitored point of the nonanchor area is in the middle of the area (i.e., $x=75 \mathrm{~mm}$ for the nonanchored area and $x=225 \mathrm{~mm}$ for the anchored area where $x$ denotes the origin of the bonding area at the load end) ranging from the load end to the boundary of the FRP sheet anchor. In the direction perpendicular to the longitudinal CFRP sheet, the monitored point location is also at the middle of the width. However, due to the different configurations of the FRP sheet anchor, the maximum bonding stress and its corresponding slip are slightly different as shown in Figure 8. In order to eliminate the different configurations of the FRP sheet anchoring effect and to obtain the unified bonding stress-slip curve, normalization work has to be done with the longitudinal axis replaced by the value of the bonding stress/ maximum bonding stress $\left(\tau / \tau_{\max }\right)$ and the transverse axis replaced by the ratio of slip to the slip at the maximum bonding stress $\left(s / s_{\max }\right)$ [43]. Figure 9 shows the corresponding normalized bonding stress-slip curves.

Figure 9 shows that the normalized bonding stress-slip curves have similar shapes in both the nonanchored and anchored areas. The simplified ideal bonding stress-slip constitutive model summarized from these curves can thus be given in Figure 10. In this shear-slip constitutive model, the bonding stress increases linearly to the peak stress $\tau_{\max }$ with the corresponding slip $S_{0}$ and then drops suddenly to the residual bonding stress $\tau_{0}$ before finally decreasing linearly with sliding at the nonanchored point. According to Leung's model [44], the slip when the shear stress decreased from the maximum shear stress for debonding to initiate $\left(\tau_{\max }\right)$ to the initial residual stress right after debonding occurs $\left(\tau_{0}\right)$ was zero (i.e., $S_{0}=0$ in Leung's model). The value of $\tau_{\max }$ can be obtained from the applied load just before the initiation of debonding (which is signified by the change in shape of the strain distribution) which can be expressed as follows:

$$
\tau_{\max }=t \alpha \sigma_{\mathrm{app}} \operatorname{coth}(\alpha L),
$$

where $t$ is the thickness of FRP; $\sigma_{\text {app }}$ is the stress of FRP exacted by the applied load just before the initiation of 


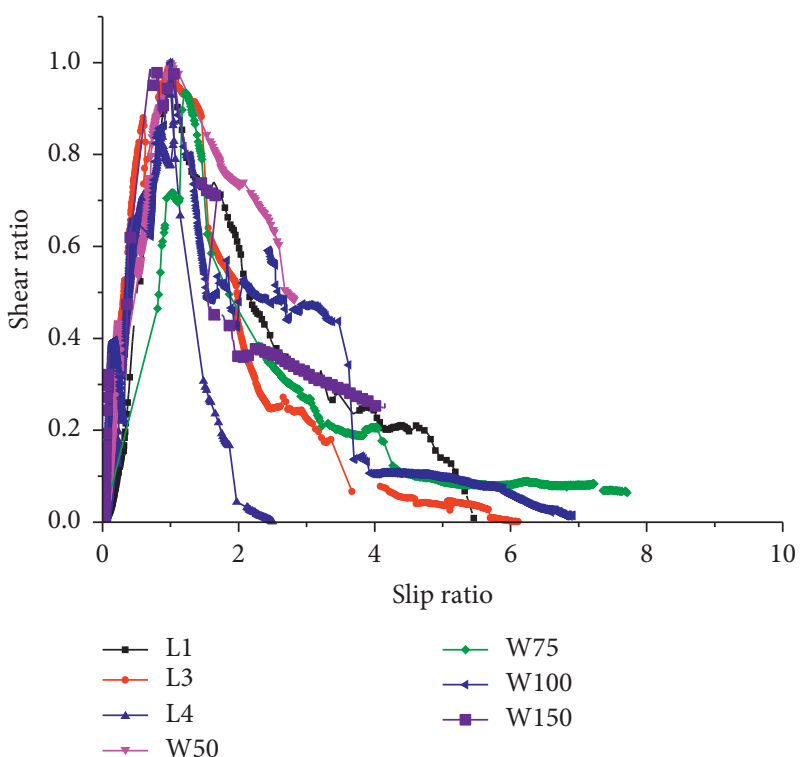

(a)

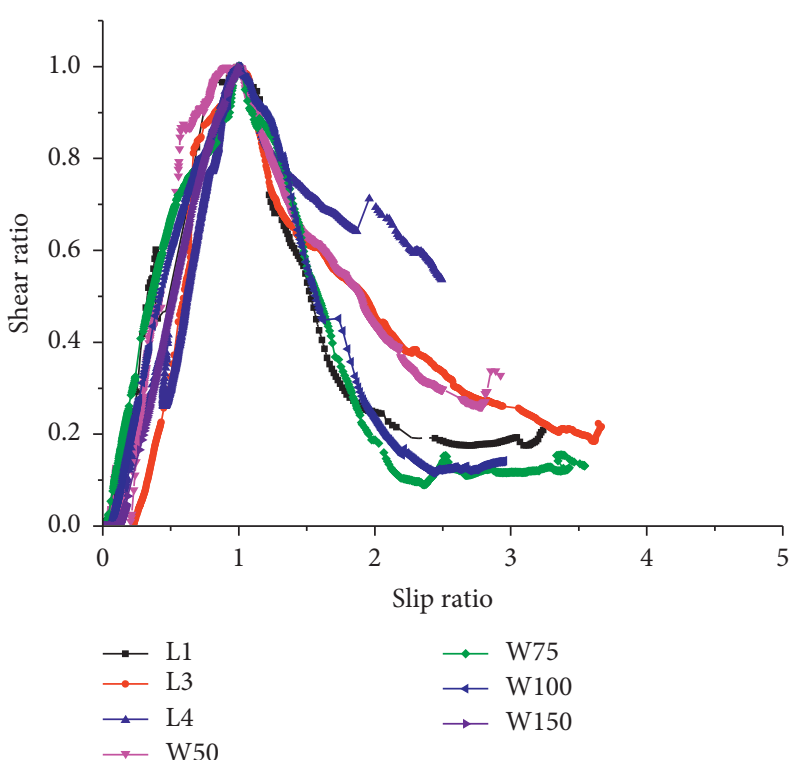

(b)

FIGURE 9: Normalized bonding stress-slip curve of the (a) nonanchored area and (b) anchored area.

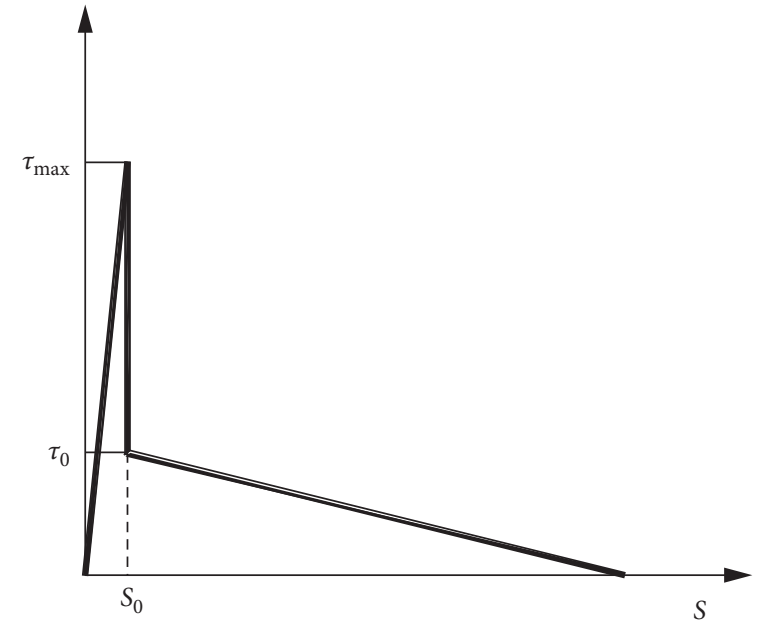

(a)

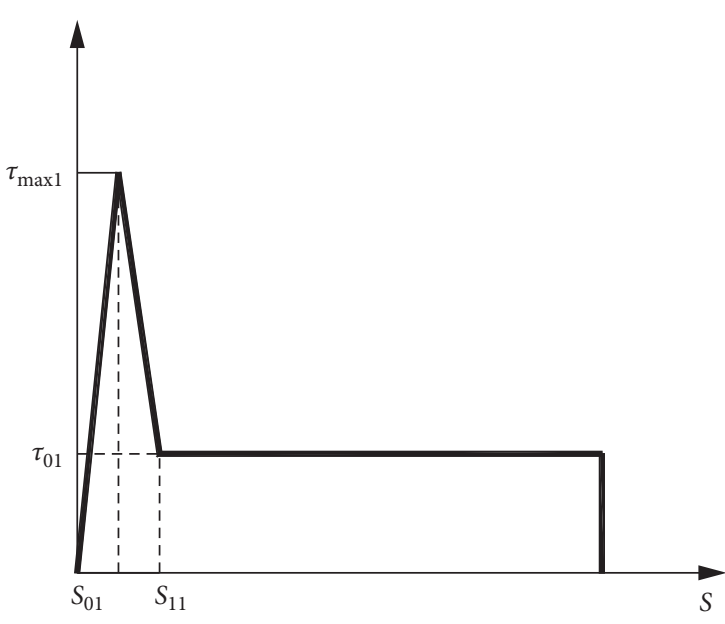

(b)

FIGURE 10: The bonding stress-slip constitutive model of the (a) nonanchored area and (b) anchored area.

debonding; $L$ is the length of bonded FRP; and $\alpha$ can be obtained by

$$
\alpha=\sqrt{\frac{G}{h t E_{f}}}\left(1+\frac{E_{f} A_{f}}{E_{c} A_{c}}\right),
$$

where $G$ is the shear modulus of the adhesive layer; $h$ is the thickness of the adhesive layer; $E_{f}$ is the elastic modulus of FRP; $A_{f}$ is the area of FRP; $E_{c}$ is the elastic modulus of concrete; and $A_{c}$ is the area of concrete.

However, the value of $\tau_{0}$ and $k$ should be obtained by a number of iterations determined from the curve fitting. If close agreement is not obtained, the parameters $\tau_{0}$ and $k$ would have to be adjusted. With the proper value of $\tau_{0}$ and $k$, the maximum slip when the shear stress decreased to zero $S_{\max }$ can be determined as follows:

$$
S_{\max }=\frac{\tau_{0}}{k} \text {. }
$$

Compared to the frictional bond-slip (FBS) model which has been proposed by Lee $[29,30]$, the general behavior is similar. In Lee's model $[29,30]$, the frictional behavior usually includes two linear stages, while in this model, this behavior is simplified into one plateau. However, it should be noted the stress-slip model for nonanchored FRP-toconcrete interface was also adopted from different models. Three stages in total make up the bonding stress-slip constitutive model of the nonanchor zone: (1) the linear growth 
stage, (2) the vertical descent stage, and (3) the much slower descent stage with further sliding, which is much like Leung's model [44].

Four stages make up the bonding stress-slip constitutive model of the anchored area. Similar to the unanchored area situation, the bonding stress first increases linearly to $\tau_{\max 1}$ at the slip $S_{01}$; then, due to the anchoring effect of the FRP sheet anchor, the bonding stress decreases much more gently than the nonanchored area at descent stage to the residual bonding stress $\tau_{01}$ at slip $S_{11}$. From this point on, the bonding stress can keep this stress level until the failure of the CFRP sheet anchor occurs. Future research could be directed toward investigating a wide range of testing parameters by conducting more experiments and FEM simulations to vivificate and improve the accuracy of this model.

\section{Conclusions}

An experimental study was conducted to investigate the anchoring effect of the FRP sheet anchor on the CFRP sheet. The width and stiffness of CFRP sheet anchor were the main experiment parameters, and the failure mechanism of the experiment was analyzed and discussed in this paper. Furthermore, an ideal constitutive bonding stress-slip model is proposed based on study of past work and observations from the experiments conducted in this study. Based on the results of this study, the following conclusions can be drawn:

(i) The utilization rate of the FRP sheet anchor are optimal when the CFRP sheet anchor width is 1.5-2 times greater than and the stiffness (number of plies) doubles in the anchored CFRP sheet. The number of plies in the CFRP sheet anchor affects the ultimate capacity and is more significant than the width of CFRP sheet anchor.

(ii) The confinement stress from the CFRP sheet anchor can increase the friction between two debonded surfaces. Meanwhile, the epoxy resin between the CFRP sheet anchor fiber can also help restrict the longitudinal CFRP sheet's movement. The anchoring effect of the CFRP sheet anchor increased the ultimate capacity from $6.85 \%$ to $41.44 \%$ in this experiment.

(iii) The simplified ideal load-slip curve under the action of the CFRP sheet anchor is depicted. At the same time, bonding stress-slip constitutive models of the anchored zone and the nonanchored zone are proposed, which are summarized from the normalized bonding stress-slip curves.

\section{Data Availability}

The data used to support the findings of this study are available from the corresponding author upon request.

\section{Conflicts of Interest}

The authors declare that they have no conflicts of interest.

\section{Acknowledgments}

The authors would like to express their thanks to the National Natural Science Foundation of China (grant nos. 51678365, 51878415, and 51908373) for funding this research.

\section{References}

[1] R. Kalfat and R. Al-Mahaidi, "Numerical and experimental validation of FRP patch anchors used to improve the performance of FRP laminates bonded to concrete," Journal of Composites for Construction, vol. 18, no. 3, pp. 318-320, 2014.

[2] S.-W. Bae and A. Belarbi, "Behavior of various anchorage systems used for shear strengthening of concrete structures with externally bonded FRP sheets," Journal of Bridge Engineering, vol. 18, no. 9, pp. 837-847, 2013.

[3] T. Skuturna and J. Valivonis, "Experimental study on the effect of anchorage systems on RC beams strengthened using FRP," Composites Part B: Engineering, vol. 91, pp. 283-290, 2016.

[4] G. El-Saikaly, A. Godat, and O. Chaallal, "New anchorage technique for FRP shear-strengthened RC T-beams using CFRP rope," Journal of Composites for Construction, vol. 19, no. 4, pp. 1-11, 2015.

[5] S. V. Grelle and L. H. Sneed, "Review of anchorage systems for externally bonded FRP laminates," International Journal of Concrete Structures and Materials, vol. 7, no. 1, pp. 17-33, 2013.

[6] H. W. Zhang and S. T. Smith, "FRP-to-concrete joint assemblies anchored with multiple FRP anchors: experimental investigation," in Proceedings of the 5th International Conference on FRP Composites in Civil Engineering (CICE 2010), Springer, Beijing, China, Advances in FRP Composites in Civil Engineering, Beijing, China, September 2010.

[7] D. A. Bournas, A. Pavese, and W. Tizani, "Tensile capacity of FRP anchors in connecting FRP and TRM sheets to concrete," Engineering Structures, vol. 82, pp. 72-81, 2015.

[8] P. V. Llauradó, T. Ibell, J. F. Gómez, and F. J. G. Ramos, "Pullout and shear-strength models for FRP spike anchors," Composites Part B, vol. 116, pp. 239-252, 2017.

[9] S. F. Breña and G. N. Mcguirk, "Advances on the behavior characterization of FRP-anchored carbon fiber-reinforced polymer (CFRP) sheets used to strengthen concrete elements," International Journal of Concrete Structures and Materials, vol. 7, no. 1, pp. 3-16, 2013.

[10] J. G. Teng, L. Lam, W. Chan, and J. Wang, "Retrofitting of deficient RC cantilever slabs using GFRP strips," Journal of Composites for Construction, vol. 4, no. 2, pp. 75-84, 2000.

[11] H. C. Biscaia and C. Chastre, "Design method and verification of steel plate anchorages for FRP-to-concrete bonded interfaces," Composite Structures, vol. 192, pp. 52-66, 2018.

[12] A. Godat, F. Ceroni, O. Chaallal, and M. Pecce, "Evaluation of FRP-to-concrete anchored joints designed for FRP shearstrengthened RC T-beams," Composite Structures, vol. 176, pp. 481-495, 2017.

[13] R. Realfonzo, E. Martinelli, A. Napoli, and B. Nunziata, "Experimental investigation of the mechanical connection between FRP laminates and concrete," Composites Part B: Engineering, vol. 45, no. 1, pp. 341-355, 2013.

[14] A. J. Lamanna, L. C. Bank, and D. W. Scott, "Flexural strengthening of reinforced concrete beams using fasteners and fiber-reinforced polymer strips," ACI Structural Journal, vol. 98, no. 3, pp. 368-376, 2001. 
[15] L. C. Bank and D. Arora, "Analysis of RC beams strengthened with mechanically fastened FRP (MF-FRP) strips," Composite Structures, vol. 79, no. 2, pp. 180-191, 2007.

[16] Y.-F. Wu and Y. Huang, "Hybrid bonding of FRP to reinforced concrete structures," Journal of Composites for Construction, vol. 12, no. 3, pp. 266-273, 2008.

[17] J. G. Teng, J. F. Chen, S. T. Smith, and L. Lam, "FRP: strengthened RC structures," John Wiley and Sons, UK, 2002.

[18] F. Ceroni, "Experimental performances of RC beams strengthened with FRP materials," Construction and Building Materials, vol. 24, no. 9, pp. 1547-1559, 2010.

[19] S. T. Smith and J. G. Teng, "Debonding failures in FRP-plated RC beams with or without U strip end anchorage," in Proceedings of the International Conference on FRP Composites in Civil Engineering, vol. I, Hong Kong, China, 2001.

[20] H. N. Garden, R. J. Quantrill, L. C. Hollaway, A. M. Thorne, and G. A. R. Parke, "An experimental study of the anchorage length of carbon fibre composite plates used to strengthen reinforced concrete beams," Construction and Building Materials, vol. 12, no. 4, pp. 203-219, 1998.

[21] R. Kotynia, H. Abdel Baky, K. W. Neale, and U. A. Ebead, "Flexural strengthening of RC beams with externally bonded CFRP systems: test results and 3D nonlinear FE analysis," Journal of Composites for Construction, vol. 12, no. 2, pp. 190-201, 2008.

[22] S. F. Breña, R. M. Bramblett, S. L. Wood, and M. E. Kreger, "Increasing flexural capacity of reinforced concrete beams using carbon fiber-reinforced polymer composites," $A C I$ Structural Journal, vol. 100, no. 1, pp. 36-46, 2003.

[23] E. S. Khalifa and S. H. Al-Tersawy, "Experimental and analytical investigation for enhancement of flexural beams using multilayer wraps," Composites Part B: Engineering, vol. 45, no. 1, pp. 1432-1440, 2013.

[24] R. Kalfat, R. Al-Mahaidi, and S. T. Smith, "Anchorage devices used to improve the performance of reinforced concrete beams retrofitted with FRP composites: state-of-the-art review," Journal of Composites for Construction, vol. 17, no. 1, pp. 14-33, 2013.

[25] S. T. Smith and J. G. Teng, "Shear-bending interaction in debonding failures of FRP-plated RC beams," Advances in Structural Engineering, vol. 6, no. 3, pp. 183-199, 2003.

[26] A. A. R. Khan and T. Ayub, "Effectiveness of U-shaped CFRP wraps as end anchorages in predominant flexure and shear region," in Advances in FRP Composites in Civil Engineering, pp. 533-536, Springer Berlin Heidelberg, Heidelberg, Germany, 2011.

[27] B. Fu, J. G. Teng, J. F. Chen, G. M. Chen, and Y. C. Guo, "Concrete cover separation in FRP-plated RC beams: mitigation using FRP U-jackets," Journal of Composites for Construction, vol. 21, no. 2, Article ID 04016077, 2017.

[28] J. H. Lee, Performance of U-wrap as an anchorage system in externally bonded FRP reinforced concrete elements, Ph.D. thesis, The Pennsylvania State University, University Park, PA, USA, 2010.

[29] J. Lee and M. M. Lopez, "Characterization of FRP U-wrap anchors for externally bonded FRP-reinforced concrete elements: an experimental study," Journal of Composites for Construction, vol. 20, no. 4, Article ID 04016012, 2016.

[30] J. Lee and M. M. Lopez, "Frictional bond-slip model for the concrete-FRP interface under the FRP U-wrap region," Construction and Building Materials, vol. 194, pp. 226-237, 2019.

[31] C. K. Y. Leung, "FRP debonding from a concrete substrate: some recent findings against conventional belief," Cement and Concrete Composites, vol. 28, no. 8, pp. 742-748, 2006.
[32] R. Al-Mahaidi and R. Kalfat, "Investigation into CFRP plate end anchorage utilising uni-directional fabric wrap," Composite Structures, vol. 93, no. 2, pp. 821-830, 2011.

[33] R. Kalfat, J. Gadd, R. Al-Mahaidi, and S. T. Smith, "An efficiency framework for anchorage devices used to enhance the performance of FRP strengthened RC members," Construction and Building Materials, vol. 191, pp. 354-375, 2018.

[34] American Concrete Institute (ACI), Guide for the Design and Construction of Externally Bonded FRP Systems for Strengthening Concrete Structures. 440.2R-17 2017, American Concrete Institute (ACI), Farmington Hills, MI, USA, 2017.

[35] Chinese Standard GB 50608, Technical Code for Infrastructure Application of FRP Composites.GB 50608-2010, China Architecture and Building Press, Beijing, China, 2010, in Chinese.

[36] Y. Zhou, Z. Fan, J. Du, L. Sui, and F. Xing, "Bond behavior of FRP-to-concrete interface under sulfate attack: an experimental study and modeling of bond degradation," Construction and Building Materials, vol. 85, pp. 9-21, 2015.

[37] J. F. Chen and J. G. Teng, "Anchorage strength models for FRP and steel plates bonded to concrete," Journal of Structural Engineering, vol. 127, no. 7, pp. 784-791, 2001.

[38] Standard C GB/T 50081-2002, Method for Testing Mechanical Properties of Normal Concrete, Standard C.GB/T, Beijing, China, 2002, in Chinese.

[39] Standard C GB/T 3354-1999, Test Method for Tensile Properties of Orientation Fiber Reinforced Polymer Matrix Composite Materials, Standard C GB/T, Beijing, China, 1999, in Chinese.

[40] http://cn.hitechfrp.com/product/zgj.html.

[41] J. Yao, J. G. Teng, and J. F. Chen, "Experimental study on FRPto-concrete bonded joints," Composites Part B: Engineering, vol. 36, no. 2, pp. 99-113, 2005.

[42] B. Ferracuti, M. Savoia, and C. Mazzotti, "Interface law for FRP-concrete delamination," Composite Structures, vol. 80, no. 4, pp. 523-531, 2007.

[43] A. Katz and N. Berman, "Modeling the effect of high temperature on the bond of FRP reinforcing bars to concrete," Cement and Concrete Composites, vol. 22, no. 6, pp. 433-443, 2000.

[44] C. K. Leung and W. K. Tung, "Three-parameter model for debonding of FRP plate from concrete substrate," Journal of Engineering Mechanics, vol. 132, no. 5, pp. 509-518, 2006. 